\title{
Perioperative anesthetic management for Cesarean section of a parturient with gestational diabetes insipidus
}

\author{
[Démarche anesthésique périopératoire pour la césarienne chez une parturiente \\ atteinte de diabète insipide gestationnel]
}

Hector J. Lacassie MD, ${ }^{*} \dagger$ Holly A. Muir MD FRCPC, ${ }^{\star}$ Simon Millar MBCHB FRCA, $\ddagger$ Ashraf S. Habib MBBCH MSc FRCA

Purpose: Gestational diabetes insipidus (GDI) is a rare endocrinopathy complicating about 4: 100,000 deliveries. We present the case of a preterm parturient with GDI and severe hypernatremia (serum sodium concentration $=174 \mathrm{mmol} \cdot \mathrm{L}^{-1}$ ) presenting for an urgent Cesarean section.

Clinical features: Fluid resuscitation and desmopressin supplementation partially corrected the patient's homeostasis, allowing us to carefully titrate epidural anesthesia for an urgent Cesarean section. After delivery, the patient was transferred to the intensive care unit. The serum sodium concentration of the mother and the neonate was normalized over $48 \mathrm{hr}$ and three days respectively.

Conclusion: The careful perioperative management of GDI led to a favourable outcome of the mother and fetus.

Objectif : Le diabète insipide gestionnel (D/G) est une endocrinopathie rare dans environ 4:100 000 accouchements. Nous présentons le cas d'une parturiente avant terme, atteinte de DIG et d'hypernatrémie sévère (sodium sérique à $174 \mathrm{mmol} \cdot \mathrm{L}^{-1}$ ), admise pour une césarienne d'urgence.

Éléments cliniques : Une thérapie liquidienne et un ajout de desmopressine ont permis de corriger partiellement l'homéostasie et d'ajuster soigneusement l'anesthésie péridurale pour la césarienne d'urgence. Après l'accouchement, la patiente a été transférée à l'unité des soins intensifs. La concentration sérique de sodium de la mère et du nouveau-né a été normalisée, respectivement après $48 \mathrm{~h}$ et trois jours.

Conclusion : La prise en charge périopératoire minutieuse du DIG a été favorable à la mère et à l'enfant.

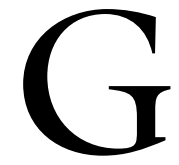

ESTATIONAL diabetes insipidus (GDI) is a rare endocrinopathy, occurring in approximately 4:100,000 pregnancies. $^{1}$ It is a potentially life threatening state if left untreated. We present the perioperative anesthetic management of a preterm parturient with GDI presenting for an urgent Cesarean section. Consent for the use of personal health information contained in this manuscript has been obtained in accordance with Duke University Medical Center Institutional Review Board guidelines.

\section{Case report}

A 25-yr-old parturient, G2Pl at 30 weeks gestation, presented to a community hospital with nausea, vomiting and polyuria increasing over three weeks. Medical history was significant for asthma and a family and personal history of myotonic dystrophy (MD). Symptoms of MD included bilateral ptosis and myotonic grip of the upper extremities. There were no cardiorespiratory symptoms. Initial treatment for hyperemesis included fluids and antiemetics; however, continued polyuria and increasing hypernatemia with clinical decline led to transfer to our teaching hospital. On admission the patient was contracting, therefore tocolysis was started with magnesium sulfate and terbutaline. Initial investigations revealed: $\mathrm{Na} 174$ $\mathrm{mmol} \cdot \mathrm{L}^{-1}$ (normal $140 \pm 5 \mathrm{mmol} \cdot \mathrm{L}^{-1}$ ), urine osmolality $133 \mathrm{mOsm} \cdot \mathrm{kg}^{-1}$ (normal $250-1200 \mathrm{mOsm} \cdot \mathrm{kg}^{-1}$ ) and serum osmolality $360 \mathrm{mOsm} \cdot \mathrm{kg}^{-1}$ (normal $285 \pm$ $\left.8 \mathrm{mOsm} \cdot \mathrm{kg}^{-1}\right)$. Laboratory testing for pre-eclampsia

From the Division of Women's Anesthesia, ${ }^{*}$ Department of Anesthesiology, Duke University Medical Center, Durham, North Carolina, USA; the Department of Anesthesiology, † Pontificia Universidad Católica de Chile, Santiago, Chile; and the Department of Anesthesia, $\ddagger$ Glasgow Royal Infirmary, Glasgow, United Kingdom.

Address corrrespondence to: Dr. Hector J. Lacassie, DUMC 3094, Bin 9, Durham, NC, 27710, USA. Phone: 919-681-6535;

Fax: 919-668-6265; E-mail: lacas001@mc.duke.edu

Accepted for publication January 17, 2005.

Revision accepted March 28, 2005. 
TABLE Laboratory values

\begin{tabular}{lllllllll}
\hline & $\begin{array}{l}\text { Glucose } \\
\left(\mathrm{mg} \cdot d l^{-1}\right)\end{array}$ & $\begin{array}{l}\text { Creatinine } \\
\left(\mathrm{mg} \cdot d l^{-1}\right)\end{array}$ & $\begin{array}{l}\mathrm{Na} \\
\left(\mathrm{mmol} \cdot \mathrm{L}^{-1}\right)\end{array}$ & $\begin{array}{l}\mathrm{Hb} \\
\left(\mathrm{g} \cdot d l^{-1}\right)\end{array}$ & $p H$ & $B E$ & $\begin{array}{l}\mathrm{HCO}_{3} \\
\left(\mathrm{mmol} \cdot \mathrm{L}^{-1}\right)\end{array}$ & $\begin{array}{l}p \mathrm{O}_{2} \\
(\mathrm{mmHg})^{*}\end{array}$ \\
\hline Admission & 72 & 1 & 174 & 11.7 & 7.35 & -2 & 23 & 365 \\
Preoperative & 110 & 0.9 & 166 & 9.1 & 7.37 & -4 & 21 & 418 \\
Immediate postoperative & 161 & 0.9 & 162 & 8.5 & 7.34 & -3 & 24 & 421 \\
\hline
\end{tabular}

*All $\mathrm{pO}_{2}$ measurements were under oxygen by facemask at $6 \mathrm{~L} \cdot \mathrm{min}^{-1}$.

was negative. Other laboratory values over the perioperative period are summarized in the Table. She was drowsy but rousable and appropriately oriented, with no localizing neurological signs.

On physical examination the most striking feature was her markedly swollen tongue, visibly protruding from her oral cavity. It was suggested by history that this occurred following the administration of an antibiotic at the referring centre, suggesting an allergic reaction, although there were no other signs of allergy and no signs of swelling beyond the oral cavity. Her airway examination revealed limited mouth opening with a Mallampati grade IV view due to the enlarged tongue occupying the entire oral cavity. There was no associated compromise in respiration. After a 10-mg dose of dexamethasone $i v$, the tongue edema improved over $90 \mathrm{~min}$, leading to a change in Mallampati view from grade IV to III.

Fetal cardiograph showed a lack of beat to beat variability with repetitive late decelerations. A decision was made that delivery of the fetus should proceed expeditiously by Cesarean section once the mother was stabilized.

Careful resuscitation was commenced with $2 \mu \mathrm{g} i v$ 1-deamino-8-D-arginine vasopressin or desmopressin (DDAVP), and dextrose $5 \%$ at $200 \mathrm{~mL} \cdot \mathrm{hr}^{-1}$ to decrease the serum sodium concentration at a rate of approximately $1 \mathrm{mmol} \cdot \mathrm{L}^{-1} \cdot \mathrm{hr}^{-1}{ }^{2}$ Arterial pressure and central venous pressure (CVP) monitoring was instituted to guide therapy. The baseline CVP value was 0 $\mathrm{mmHg}$, blood pressure $135 / 55 \mathrm{mmHg}$ and heart rate $110 \cdot \mathrm{min}^{-1}$. The CVP increased to $4 \mathrm{mmHg}$ following fluid resuscitation. A lumbar L2-L3 epidural catheter was then placed for Cesarean section. Four boluses of $5 \mathrm{~mL}$ ropivacaine $0.5 \%$ were administered incrementally over $20 \mathrm{~min}$, in addition to $75 \mu \mathrm{g}$ epidural fentanyl, with further $10 \mathrm{~mL}$ of lidocaine $2 \%$ to achieve a bilateral T4 sensory level. The CVP was $2 \mathrm{mmHg}$ following administration of the epidural local anesthetics. The patient remained stable hemodynamically, with an oxygen saturation of $100 \%$ throughout the procedure (oxygen $6 \mathrm{~L} \cdot \mathrm{min}^{-1}$ was delivered by facemask). With the T4 sensory level, good surgical anesthesia was achieved. Of concern however, during the course of the operative procedure, was increasing somnolence of the mother. The woman was admitted to the intensive care unit (ICU) after delivery for further evaluation and stabilization. The serum $\mathrm{Na}$ concentration was $166 \mathrm{mmo} \cdot \mathrm{L}^{-1}$ and $162 \mathrm{mmol} \cdot \mathrm{L}^{-1}$ immediately prior to the Cesarean section and upon admission to the ICU, respectively.

A male infant with Apgar scores 1, 4, 5, at one, five, and ten minutes respectively was delivered. Fetal cord blood samples revealed $\mathrm{pH} 7.13$, base excess - 4, total $\mathrm{CO}_{2} 30 \mathrm{mmol} \cdot \mathrm{L}^{-1}$ and $\mathrm{Na} 168 \mathrm{mmol} \cdot \mathrm{L}^{-1}$. Upon admission to the neonatal ICU, a decision to institute mechanical ventilation was made due to persistent hypotonia and poor respiratory effort. Free water was delivered to the baby and serum sodium normalized over the next three days. The neonate was weaned quickly off ventilatory support.

The mother's sodium concentration was corrected by $48 \mathrm{hr}$ post-delivery in the ICU. Mental state lagged behind metabolic restoration; however, neurologic studies which included a computed tomography scan were normal. On postoperative day three, the patient developed acute pancreatitis, requiring a prolonged ICU stay. She was discharged home 29 days after admission.

\section{Discussion}

This is the first report in the English literature describing the perioperative anesthetic management for Cesarean section of a parturient with GDI and severe hypernatremia.

Diabetes insipidus is a syndrome characterized clinically by excretion of abnormally large volumes of dilute urine. ${ }^{3}$ It is caused by a dysfunction in the interaction of antidiuretic hormone, also known as arginine vasopressin (AVP) and the vasopressin receptors in the distal convoluted tubules and collecting ducts of the renal medulla, ${ }^{4}$ resulting in solute free water loss in the urine and hypernatremia. GDI results from increased metabolism of AVP. ${ }^{3}$ The pregnant state may induce 
diabetes insipidus or unmask previous subclinical diabetes insipidus. ${ }^{1}$ The mechanisms involved are 1) decreased renal responsiveness to AVP; 2) increased placental production of vasopressinase (a cystine aminopeptidase), with decreased availability of AVP due to four- to sixfold increased degradation by placental vasopressinase,${ }^{5} 3$ ) a decrease in plasma sodium concentration by approximately $5 \mathrm{mmol} \cdot \mathrm{L}^{-1}$, with a decrease in plasma osmolality setpoint for AVP release of 5 to $10 \mathrm{mOsm} \cdot \mathrm{kg}^{-1}$; and 4) a decreased thirst threshold. $1,3,5$

An association between GDI with fatty liver of pregnancy and pre-eclampsia has been previously reported. ${ }^{6,7}$ The signs and symptoms of GDI may recur with subsequent pregnancies. ${ }^{8}$

Definite treatment of GDI is delivery of the placenta. ${ }^{3}$ However during pregnancy, DDAVP is the drug of choice for treatment as well as for making a definitive diagnosis, as it is not metabolized by placental vasopressinase, thus allowing one to make a pathophysiological distinction of the disease. The recommended $i v$ dose is 1 to $4 \mu \mathrm{g}$. ${ }^{9}$ Symptomatic treatment is based upon slow correction of water deficit to normalize natremia and osmolality. The renal medulla needs to readapt to the new homeostasis, which takes three to six weeks to occur. ${ }^{4}$

The major clinical manifestations of hypernatremia involve the central nervous system and include altered mental status, weakness, neuromuscular irritability, focal neurologic deficits, seizures and coma. ${ }^{10}$ Mortality associated with hypernatremia is around 40 to $55 \%$, however it is unclear if hypernatremia is the cause or a marker of severe associated disease. ${ }^{11}$

In our patient, GDI presented with polyuria associated with altered mentation secondary to hypernatremia, which developed over a few weeks. The diagnosis was based upon increased serum osmolality, decreased urine osmolality $\left(<200 \mathrm{mOsm} \cdot \mathrm{kg}^{-1}\right)$, recovery of her symptoms after placental delivery, and a favourable response to DDAVP. Differential diagnosis for our patient's increased somnolence intra- and postoperatively could include, in addition to the metabolic derangement, the possible systemic effects of the epidural fentanyl or minor local anesthetic toxicity. However, this is unlikely since there were no other manifestations of local anesthetic toxicity. The slow improvement of her mental status over the next days suggests that the patient's altered mentation was secondary to delirium produced by the severe metabolic derangement.

Management of this patient started preoperatively and included a thorough assessment, invasive monitoring and initial correction of water deficit. Full cor- rection of the metabolic abnormalities was not possible preoperatively in this case, due to the urgent nature of the Cesarean section and because correction of hypernatremia should be carried out carefully and gradually to avoid cerebral edema. Rapid correction of hypertonicity to a normal serum osmolality is hazardous. Because accumulation of idiogenic osmoles by brain cells is a compensatory mechanism for preserving brain volume in hypertonic disorders, a normal serum osmolality may be relatively hypotonic to brain cells that have accumulated idiogenic solutes. Hence, if the serum osmolality is reduced rapidly, central nervous system damage due to brain swelling may occur. It is suggested to reduce the serum sodium level by no more than $1 \mathrm{mmol} \cdot \mathrm{L}^{-1} \cdot \mathrm{hr}^{-1}{ }^{2}$ In our patient the water deficit was over $6 \mathrm{~L}$ (based on the formula: water deficit $=0.5 \times$ weight $(\mathrm{kg}) \times((\mathrm{Na}$ measured $\times(\mathrm{Na}$ target $\left.\left.)^{-1}\right)-1\right) .{ }^{12}$

For the intraoperative period we decided to avoid general anesthesia because of the risks involved in this patient, namely a difficult airway because of a swollen tongue. In addition were the inherent potential airway problems in a pregnant patient, as well as a possible interaction of the MD state with general anesthetics, particularly an exaggerated depressant effects of opioids and triggering of myotonia by succinylcholine, which may make ventilation and intubation even more difficult. ${ }^{13}$ We administered an epidural, rather than a spinal anesthetic, to achieve a surgical block in an incremental and controlled fashion in the face of intravascular volume deficit, as diagnosed clinically and confirmed by the low CVP readings. Postoperatively, the patient was managed in the ICU to allow for continued resuscitation and correction of the metabolic abnormalities.

Since the management of regional anesthesia in the presence of such a severe degree of hypernatremia was not previously reported, we had some uncertainty about the action of local anesthetics in face of this extreme metabolic abnormality. While hypernatremia can lead to an increase in volatile agents' minimum alveolar concentration, ${ }^{14}$ the only information on altered requirements of local anesthetics in hypernatremia is an assumption that hypernatremia raises transmembrane sodium gradient, and subsequently the local anesthetic minimum blocking concentration $(\mathrm{Cm}) .{ }^{15}$ Since there is a strong correlation between intra- and extra-neural sodium ion concentration (transmembrane sodium gradient) and resting membrane potential, one would expect to see some correlation between local anesthetic potency $(\mathrm{Cm})$ and serum sodium concentration (de Jong, personal communication). In our patient, there was no evidence of 
altered sensitivity to local anesthetics. However, it must be noted that we probably used supramaximal doses that may have overridden a slight increase in $\mathrm{Cm}$. When using low doses, as for labour epidural analgesia, such an effect might be observed.

In summary, we present a case of GDI in which careful perioperative management led to a favourable outcome of mother and fetus.

\section{References}

1 Iwasaki $\Upsilon$, Oiso $\Upsilon$, Kondo K, et al. Aggravation of subclinical diabetes insipidus during pregnancy. $\mathrm{N}$ Engl $\mathrm{J}$ Med 1991; 324: 522-6.

2 Adrogue HJ, Madias NE. Hypernatremia. N Engl J Med 2000; 342: 1493-9.

3 Robertson GL. Diabetes insipidus. Endocrinol Metab Clin North Am 1995; 24: 549-72.

4 Robertson GL. Antidiuretic hormone. Normal and disordered function. Endocrinol Metab Clin North Am 2001; 30: 671-94 vii.

5 Lindheimer MD, Davison JM. Osmoregulation, the secretion of arginine vasopressin and its metabolism during pregnancy. Eur J Endocrinol 1995; 132: $133-43$.

6 Barbey F, Bonny O, Rothuizen L, Gomez F, Burnier M. A pregnant woman with de novo polyuria-polydipsia and elevated liver enzymes. Nephrol Dial Transplant 2003; 18: 2193-6.

7 Kennedy S, Hall PM, Seymour AE, Hague WM. Transient diabetes insipidus and acute fatty liver of pregnancy. Br J Obstet Gynaecol 1994; 101: 387-91.

8 Laszlo FA, Czako L. 1-deamino-/4-valine-8-D-arginine/-vasopressin (dVDAVP), a new synthetic vasopressin analog for treating diabetes insipidus. Int $\mathrm{J}$ Clin Pharmacol Ther Toxicol 1982; 20: 39-43.

9 British Medical Association and Royal Pharmacentical Society of Great Britain. British-National-Formulary.

Desmopressin, 48 ed. London: British Medical Association and Royal Pharmaceutical Society of Great Britain; 2004.

10 Singer G, Brenner B. Fluid and electrolyte disturbances. In: Braunwald E, Harrison TR (Eds). Harrison's Principles of Internal Medicine, 15th ed. New York: McGraw-Hill Medical Pub. Division; 2001: 271-82.

11 Fried LF, Palevsky PM. Hyponatremia and hypernatremia. Med Clin North Am 1997; 81: 585-609.

12 Rose B. Clinical Physiology and Acid Base and Electrolyte Disorders, 4th ed. McGraw-Hill; 1994: 720-3.

13 Bader $A M$. Neurologic and neuromuscular disease. In: Chestnut D (Ed.). Obstetric Anesthesia. Principles and Practice, 2nd ed. St. Louis, Mosby, Inc.; 1999:

963-85.
14 Tanifuji $\Upsilon$, Eger EI 2nd. Brain sodium, potassium, and osmolality: effects on anesthetic requirement. Anesth Analg 1978; 57: 404-10.

15 De Jong $R H$. Local Anesthetics, lst ed. St. Louis, Mosby; 1994: 230-49. 